\title{
De las neuronas espejo a la neuropolítica moral ${ }^{*}$
}

\author{
Gary Olson ${ }^{* *}$
}

Resumen: Este artículo presenta el descubrimiento del sistema de neuronas espejo, que muestran que los mecanismo neuronales revelan que los humanos estamos «cableados" para la empatía, con lo que la moralidad tendría así sus raíces en la biología. Se argumenta que esta base científica tenderá a influir la opinión pública contribuyendo a disolver nuestras creencias actuales que nos llevan a la destrucción recíproca. La pregunta pendiente, se señala, es por qué no actúa la empatía a nivel social, formulándose propuestas de respuesta desde la influencia cultural sobre lo biológico.

Palabras clave: neuronas espejo, neuropolítica, biología, cultura, moral.

\section{From mirror neurons to moral neuropolitics}

Abstract: This article presents the discovery of the mirror neurons system, which shows that neuronal mechanisms reveal that humans are "wired" for empathy, with what morality would have its roots in biology. It is argued that this scientific base will tend to influence public opinion, contributing to dissolve our current beliefs that carry us to reciprocal destruction. The pending question, is indicated, is why doesn't empathy act in the social level, with answering proposals being formulated in the line of cultural influence over biological reality.

Keywords: mirror neurons, neuropolitics, biology, culture, moral.

Recibido: 10.05 .08

Aceptado: 21.07.08

En todo el mundo, los profesores, sociólogos, políticos y padres están descubriendo que la empatía puede ser la cualidad más importante que hay que alimentar para darle a la paz la oportunidad de vencer. Arundhati Rai

Las directrices oficiales no necesitan ser explícitas para que se las comprenda bien: no debe permitirse que demasiada empatía se mueva en direcciones no autorizadas.

\footnotetext{
${ }^{*}$ Una versión muy abreviada de este artículo apareció en www.zmag.org (5/20/07) y fragmentos en www.identitytheory.com (10/16/07). Quiero agradecer los interesantes comentarios que hicieron sobre los primeros borradores N. Chomsky, D. Dunn, M. Iacoboni, K. Kelly, S. Preston, y J. Wingard. Gracias, como siempre, a M. Ortiz. Traducción de Anahí Seri para Rebelión donde fue publicada en forma parcial en http://www.rebelion.org/noticia.php?id=66870.

${ }^{*}$ Moravian College, Bethlehem, PA., USA. Email: olson@moravian.edu. 
Steven Pinker, el psicolingüista de Harvard, concluye un reciente artículo sobre la ciencia de la moralidad (2008) con estas palabras de Antonio Chejov, desafiantes pero llenas de esperanza: "El hombre llegará a ser mejor si le muestras cómo es." En este contexto, la fundación sin ánimo de lucro EDGE recientemente preguntó a algunos de los científicos más eminentes del mundo “QQué le hace sentirse optimista? y¿Por qué?” Como respuesta, el destacado neurocientífico Marco Iacoboni cita el trabajo experimental que se está prodigando sobre los mecanismo neuronales que revelan que los humanos están "cableados para la empatía". Se trata del descubrimiento, relativamente reciente, del sistema de neuronas espejo (SNE).

El optimismo de Iacoboni se funda en su convicción de que, al divulgarse estos hallazgos científicos, estos recientes descubrimientos de neurociencia calarán en la conciencia pública y “.... este nivel explícito de comprensión de nuestra naturaleza empática en algún momento disolverá los sistemas masivos de creencias que dominan nuestras sociedades y amenazan con destruirnos" (Iacoboni, 2007, p. 14, 2008).

Lo que subyace a todo esto son los experimentos neurocientíficos que muestran que cuando uno percibe el dolor de los otros se movilizan automáticamente los mismos circuitos neuronales afectivos que cuando siente su propio dolor.

En 1996, a través de grabaciones de una sola célula en los macacos, los investigadores informaron del descubrimiento de un tipo de células del cerebro denominadas "neuronas espejo" (Gallese, 1996). Situadas en el área F5 de la corteza premotora, estas neuronas espejo disparaban no sólo cuando el mono realizaba una acción, sino también cuando el mono observaba a otro realizando la misma acción. Las neuronas del mono reflejaban, como en un espejo, la actividad que estaba observando. Posteriormente, cartografiando las regiones del cerebro humano mediante la Resonancia Magnética funcional (RMf), se descubrió que las áreas humanas de las que se suponía que contenían neuronas espejo también comunicaban con el sistema límbico, o emocional, facilitando la conexión con los sentimientos de otra persona, probablemente reflejando estos sentimientos. Se cree que estos circuitos neuronales constituyen la base del comportamiento empático, en el cual las acciones en respuesta a la aflicción de los demás son prácticamente instantáneas. Como dice Goleman, "el que este flujo de la empatía a la acción ocurra de modo tan automático hace pensar en unos circuitos dedicados precisamente a esta secuencia." Por ejemplo, cuando uno oye el grito angustiado de un niño, "la aflicción que siente impulsa la necesidad de ayudar" (Goleman, 2006, p. 60).

La existencia de la empatía, de neuronas espejo, no era más que una inferencia a partir de estos estudios de RMf. Pero en 2007, Iacoboni, el neurocirujano Itzhak Fried y sus asociados en la Universidad de California en Los Angeles (UCLA) estudiaron la actividad cerebral en personas a las que Fried ya había cableado, intentando dar con los orígenes de los ataques de epilepsia. Insertando electrodos en los lóbulos frontales, este equipo de 
científicos identificó varias neuronas espejo que se activaban con la realización y también con la observación de una actividad.

Valayanur Ramachandran, director del Centro del Cerebro y la Cognición en la Universidad de California en San Diego (UCSD), observa: "Decíamos, usando una metáfora, 'siento el dolor del otro', pero ahora sabemos que mis neuronas espejo pueden sentir, literalmente, tu dolor." (Slack, 2007). Ramachandran, que las llama "neuronas de empatía" o "neuronas Dalai Lama", escribe que "Esencialmente, la neurona es parte de una red que te permite ver el mundo "desde el punto de vista de otra persona", de ahí el nombre 'neurona espejo' ". (Ramachanddran, 2006).

Giacomo Rizzolatti, el neurocientífico italiano que descubrió las neuronas espejo, señala que este sistema cableado es lo que nos permite "captar las mentes de los demás no a través de un razonamiento conceptual sino a través de una estimulación directa de los sentimientos, no con el pensamiento" (Rizzolatti en Goleman, 2006). Como hace notar Decety, la empatía nos permite "forjar conexiones con gente cuyas vidas parecen totalmente ajenas a nosotros" (Decety, 2006, p.2). Cuando se carece de una experiencia comparable, esta "empatía cognitiva" se construye sobre la base neural y nos permite "proyectarnos activamente dentro de otra persona" intentando imaginar la situación de la otra persona (Preston, en prensa), Preston y de Waal (2002). La empatía está "dirigida hacia el otro" y reconoce la cualidad humana del otro. No es sorprendente que algunos científicos piensen que el descubrimiento de las neuronas espejo es el hallazgo neurológico más importante desde hace décadas, y que podría rivalizar con lo que el descubrimiento del ADN significó para la biología. (Ramachandran, 2006).

Hay un paralelismo entre la neurociencia de la empatía y las investigaciones que se están desarrollando en campos relacionados. Hace unos cuarenta años, la célebre primatóloga Jane Goodall observó y escribió sobre las emociones de los chimpancés, sus relaciones sociales y la "cultura de los chimpancés", pero los expertos mantuvieron un gran escepticismo. Hace una década, el famoso etólogo especialista en primates Frans B.M. de Waal (1996) escribió sobre los antecedentes de la moralidad en "Bien Natural: Los orígenes del bien y del mal en los humanos y los otros animales", pero el consenso científico aún se hacía esperar. Todo ello ha cambiado. Como afirma un reciente editorial de la revista Nature (2007), hoy es un "hecho incontestable" que las mentes humanas, incluidos los aspectos del pensamiento moral, son el producto de la evolución a partir de primates anteriores. Según de Waal, "ya no hay debate". En su obra más reciente, de Waal argumenta de forma convincente que la moralidad humana -incluida la capacidad de sentir empatía- es un subproducto natural, o una herencia de comportamiento de nuestros parientes evolutivos más próximos.

Siguiendo a Darwin, unos estudios muy sofisticados hechos por los biólogos Robert Boyd y Peter Richerson postulan que la cooperación a gran escala dentro de la especie humana (incluso con individuos no emparentados genéticamente dentro de un grupo) fue 
favorecida por la selección. (Hauser, 2006, p. 416) La evolución seleccionó el rasgo de la empatía porque el hecho de entenderse con los demás entraña ventajas para la supervivencia. En su libro People of the Lake ("La gente del lago")(1978), el paleoantropólogo de fama mundial Richard Leakey declara categóricamente: "Somos humanos porque nuestros antepasados aprendieron a compartir su comida y sus habilidades en un red de compromisos que se cumplían."

Hay estudios que demuestran que la empatía está presente en niños de muy corta edad, incluso de 18 meses o aún menores. En el mundo de los primates, Warneken y sus colegas en el Instituto Max Planck de Leipzig, Alemania, hallaron recientemente que los chimpancés prestan ayuda incluso a chimpancés no emparentados y a humanos que no conocen, aún cuando eso les supone una molestia y sin que tengan expectativas de recompensa. Esto sugiere que la empatía puede explicar esta tendencia natural de ayudar, y que fue un factor en la vida social del antepasado común de chimpancés y humanos cuando sus líneas se dividieron, hace unos seis millones de años (New Scientist, 2007; Warneken y Tomasello, 2006). Actualmente ya no se cuestiona que compartimos las facultades morales con otras especies (de Waal, 2006; Trivers, 1971; Katz, 2000; Gintis, 2005; Hauser, 2006; Bekoff, 2007; Pierce, 2007). Pierce señala que hay "innumerables anécdotas de elefantes que muestran empatía hacia animales enfermos y moribundos, emparentados o no (2007, p. 6). Y recientes investigaciones en Kenia demuestran de forma incontestable el duelo exteriorizado del elefante, su empatía hacia otros elefantes muertos.

Mogil y su equipo en la Universidad McGill demostraron recientemente que los ratones sienten ansiedad cuando observan a otros ratones que sienten dolor. Concluyeron, de forma provisional, que los ratones empleaban pistas visuales para la generación de esta respuesta empática (Mogil, 2006; Ganguli, 2006). De Waal responde así al estudio: "Se trata de un hallazgo muy significativo, que debería abrir los ojos de la gente que piensa que la empatía se limita a nuestra especie" (Carey, 2006).

Además, Grufman y otros científicos en los Institutos Nacionales de Salud han proporcionado pruebas persuasivas de que las acciones altruistas activan una parte primitiva del cerebro, dando lugar a una respuesta placentera (2007). Y las recientes investigaciones de Koenigs y sus colegas (2007) indican que dentro de la corteza prefrontal, la corteza prefrontal ventromedial (VMPC) es necesaria para las emociones y los juicios morales. Los daños en la VMPC se han relacionado con comportamientos psicópatas, y los individuos con tendencias psicópatas muestran una gran carencia de empatía (Blair, 2005, pp. 53-56).

Un estudio a cargo de Miller (2001) y sus colegas sobre la demencia frontotemporal (DFT) también resulta instructiva. La DFT ataca los lóbulos frontales y los lóbulos temporales anteriores, donde reside la conciencia de sí mismo. Un primer síntoma de DFT es la pérdida de empatía, y la actividad de las ondas cerebrales de las neuronas espejo en los individuos autistas muestra que no disparan correctamente. 
Si bien hay razones para mantenerse escéptico (véase más abajo) en relación con las implicaciones políticas progresistas que se desprenden de estos trabajos, un cuerpo de pruebas empíricas impresionantes revela que las raíces del comportamiento prosocial, incluidos sentimientos morales como la empatía, preceden a la evolución de la cultura. Este trabajo apoya los escritos visionarios de Noam Chomsky sobre el instinto moral humano y su afirmación de que, si bien los principios de nuestra naturaleza moral no se han llegado a comprender bien, "no cabe duda de su existencia y de su función central en nuestras vidas intelectuales y morales" (Chomsky, 1971, n.p., 1988; 2005, p. 263).

En su influyente libro Ayuda mutua(1902), Petr Kropotkin, naturalista, geógrafo y anarquista revolucionario ruso mantuvo que "...en cualquier circunstancia la sociabilidad es la mayor ventaja en la lucha por la vida. Aquellas especies que la abandonan están condenadas a la decadencia." La cooperación proporcionaba una ventaja evolutiva, una "estrategia" de supervivencia natural.

Kropotkin no tuvo inconveniente en admitir la función de la competencia, pero afirmó que la ayuda mutua era un "instinto moral" y una "ley natural". Basándose en sus amplios estudios del mundo animal, pensaba que esta predisposición a ayudarse mutuamente (la sociabilidad humana) era de "origen prehumano". Killen y Cords, en un artículo titulado "Prince Kropotkin's Ghost (El fantasma de Kropotkin)," sugieren que la investigación reciente en psicología del desarrollo y primatología parece confirmar las afirmaciones que hizo Kropotkin hace un siglo (2002).

Así pues, ¿dónde estamos? Si la moralidad tiene sus raíces en la biología, en la materia prima o los ladrillos para la evolución de su expresión, tenemos ahora pendiente un matrimonio fortuito entre las ciencias duras y la moralidad laica en su sentido más profundo. Los detalles técnicos del análisis neurocientífico social que apoya estas afirmaciones quedan fuera de este artículo, pero baste con señalar que se está avanzando a un ritmo exponencial, que los nuevos descubrimientos son persuasivos (Iacoboni, 2008; Lamm, 2007; Jackson, 2006) y nuestra comprensión de la empatía ha aumentado dramáticamente en apenas una década.

Dicho lo cual, uno de los problemas más fastidiosos que quedan por explicar es por qué se ha avanzado tan poco en lo que supone extender esta orientación empática hacia las vidas distantes, a aquellos que se encuentran fuera de determinados círculos morales de camarillas. Es decir, dado un mundo colmado de violencia abierta y estructural, nos vemos obligados a explicar por qué nuestra intuición moral profundamente arraigada no tiene mayor efecto de mejora, por qué no produce un mundo más pacífico. Iacoboni sugiere que esta desconexión se explica por los sistemas masivos de creencias, incluidos los políticos y los religiosos, que operan a nivel de reflexión y deliberación. Como nos recuerda de Waal, desde el punto de vista evolutivo, la empatía es el punto de partida original del cual emanaron la cultura y el lenguaje. Pero a lo largo del tiempo, la cultura filtra e influye en el 
modo en que la empatía evoluciona y se expresa. (de Waal, 2007, p. 50) Estos sistemas de creencias tienden a invalidar los rasgos automáticos, pre-reflexivos, neurobiológicos que deberían unir a la gente. Iacoboni plantea como hipótesis la presencia de lo que él denomina súper neuronas espejo en el lóbulo frontal del cerebro. Estas super neuronas espejo, más complejas, muy desarrolladas, tal vez controlen a las neuronas llamadas de bajo nivel, o clásicas. Esta investigación, que podría considerarse que hoy por hoy constituye la cúspide de los trabajos más avanzados en neurociencias, se encuentra es una fase preliminar, pero es posible que los futuros estudios sugieran cómo la resistencia cognitiva consigue clasificar, inhibir o modular de otro modo las respuestas neurofisiológicas.

Así pues, hay que proceder con cautela. En primer lugar, hay que advertir que el contexto social y las condiciones que desencadenan la respuesta son críticas, ya que, cuando existe una manipulación de la élite, consciente y masiva, se vuelve cada vez más difícil entrar en contacto con nuestras facultades morales. Ervin Staub, un investigador pionero en este campo, admite que incluso si la empatía tiene sus raíces en la naturaleza, las personas no se guiarán por ella "...a menos que tengan un cierto tipo de experiencias vitales que dirijan su orientación hacia otros seres humanos y hacia sí mismos" (Staub, 2002, p. 222). Como dice Jensen, "El modo en que se nos educa y se nos entretiene evita que nos enteremos, o que entendamos, el dolor de los demás “ (2002, 2008). Las circunstancias pueden bloquear o abrumar nuestras percepciones, volviéndonos incapaces de reconocer y dar expresión a nuestros sentimientos morales (Albert, n.d.; y también, Pinker, 2002). Por ejemplo, si se infunde temor de una escasez creada artificialmente, esto puede atenuar la respuesta empática.

Luego están las limitaciones a las que están sujetas las imágenes poderosas que podrían despertar profundas emociones en el público americano. Un ejemplo es la reciente destrucción de las cintas de video de la CIA en las que se ve la tortura de prisioneros. El centro médico regional de Landstuhle, en Alemania, que acoge de forma habitual soldados procedentes de Irak con grotescas mutilaciones, no permite fotografías, y los periodistas son supervisados por escoltas militares. Y sabemos que el Pentágono prohíbe la cobertura fotográfica en los medios de comunicación de los restos de soldados que salen de la base aérea alemana Ramstein o de los ataúdes que regresan a Dover, Delaware. (Tami Silco, quien tomó la foto -ahora célebre- de 20 ataúdes envueltos en banderas que salían de Kuwait, perdió su empleo). Asimismo, se prohíbe la cobertura de los funerales por los caídos, incluso si la unidad da su aprobación.

La segunda nota de advertencia es la observación de Hauser (2006) de que la proximidad fue sin lugar a dudas un factor en la expresión de la empatía. En nuestro pasado evolutivo, el apego a la familia humana más amplia era prácticamente incomprensible y por tanto se carecía de la conexión emocional. Joshua Greene, filósofo y neurocientífico, añade que "Evolucionamos en un mundo en el que teníamos delante a personas en apuros, por tanto nuestras emociones sintonizaban con ellas, pero no nos enfrentábamos al otro tipo de 
situación." Sugiere que el extender esta moralidad inmediata, ligada a la emoción (basada en circuitos fundamentales del cerebro) a víctimas que no vemos, requiere que se preste menos atención a la intuición y más a la dimensión cognitiva. Si este límite no es artificioso, parecería, como mínimo, circunstancial, y así pues merecería que se reevaluará la moralidad (Greene, 2007, n.p.). Dadas algunas de las dimensiones positivas de la globalización, el potencial de identificarse con el "extraño" nunca ha sido más prometedor.

Pero no en todos los casos. Carlisle (2007) señala que a través del empleo de la tecnología (incluido el matar a gran distancia, y nuevos tipos de entrenamiento) el ejército ha intentado desensibilizar y sortear la respuesta empática natural que la mayoría de los soldados sienten hacia sus adversarios. Advierte que "...con menos oportunidades de conseguir unos reflejos del sufrimiento de otros humanos, que dan lugar a la empatía, con el tiempo es posible que nuestra capacidad para la empatía desaparezca del todo." Para un atento estudio de la aversión humana innata hacia quitar la vida, y de cómo el ejército ha condicionado a los soldados para que lo superen (con el consiguiente daño psicológico) la mejor referencia es Lt. Col. David Grossman, On Killing (1996).

Puede ser útil, como sugiere Halpern (1993, p. 169), pensar en la empatía como una especie de chispa de la curiosidad natural, que despierta la necesidad de comprender mejor, y un cuestionamiento más profundo. Sin embargo, nuestra comprensión de cómo o en qué medida se sigue de ahí un compromiso político, sigue siendo muy limitada, y queda mucho trabajo por hacer. Hace casi un siglo, Stein (1917) se refirió a la empatía como a la "experiencia de la conciencia ajena en general". La película Diarios de motocicleta de Salles trata de la empatía, si bien de forma indirecta. La película sigue a Ernesto Guevara de la Serna y su amigo Alberto Granada en un viaje de ocho meses por Argentina, Perú, Colombia, Chile y Venezuela.

Cuando sale de su barrio residencial de clase media alta (su padre es arquitecto) en Buenos Aires en 1952, Guevara tiene 23 años y le queda un semestre para licenciarse en medicina. Los jóvenes se embarcan en una aventura, deciden echar una cana al aire antes de establecerse e iniciar una vida acomodada. Les interesan las mujeres, la diversión y la aventura, y desde luego que ni buscan ni esperan un odisea que cambie sus vidas.

El poder de la película estriba en la forma en que se describe cómo nace la conciencia política de Guevara, a consecuencia de una acumulación de experiencias no filtradas. Durante su viaje de $5.000 \mathrm{~km}$, se encuentran con pobreza masiva, explotación y condiciones de trabajo brutales, todo ello consecuencia de un orden económico internacional injusto. Al final, Guevara abandona la idea de ser médico porque la medicina se limita a tratar los síntomas de la pobreza. Para él, la revolución se convierte en la expresión de la empatía, la única forma efectiva de tratar las raíces del sufrimiento. Esto requiere fusionar el componente cognitivo de la empatía con el compromiso, con la 
resistencia contra el poder asimétrico, siempre un acto inherentemente político. Si no, la empatía carece de significado. (Esto guarda un cierto paralelismo con la práctica política de brahma-viharas por parte de budistas comprometidos.) En sus propias palabras, que se citan a menudo (no se incluyeron en la película), Guevara afirmó que "el revolucionario verdadero está guiado por grandes sentimientos de amor".

Paul Farmer, antropólogo médico, especialista en enfermedades infecciosas y activista internacional de salud pública, contemporáneo, ha adoptado unas tácticas distintas, pero su diagnóstico de las "patologías del poder" se parece mucho al de Guevara. Él también alaba los programas de salud de Cuba, comparándolos con su larga experiencia de trabajo en Haití. Ambos estuvieron muy motivados por la creencia de que las epidemias artificiales tienen su origen en estructuras socioeconómicas injustas, de ahí la necesidad de una medicina social, una "política como medicina a gran escala". Ambos veían la "política como medicina a gran escala" y se comprometieron a actuar en nombre de los pobres. Ambos son un ejemplo excepcional de algo que se sale de la norma social, empatía comprometida y una interrelación de componentes afectivos, cognitivos y morales. Véase la radical crítica que hace Farmer de la violencia estructural y las conexiones entre enfermedad y desigualdad social en (Farmer, 2003; Kidder, 2003). Una vez más, queda por explicar por qué hay tal escasez de ejemplos de comportamiento empático en el mundo real. ¿Por qué se caracteriza la cultura de USA por un déficit masivo de empatía de proporciones casi patológicas? ¿Y qué cabría esperar, razonablemente, de una comprensión pública más amplia de la naturaleza de la empatía?

Hauser postula una "gramática moral universal", cableada en nuestros circuitos neurales a través de la evolución; esta maquinaria neural es anterior a las decisiones conscientes en situaciones de vida o muerte. Sin embargo, observamos que "la crianza entra en juego para fijar los parámetros y guiarnos hacia la adquisición de unos sistemas morales particulares." En otro lugar, Hauser sugiere que los factores ambientales pueden impulsar a los individuos hacia una razonamiento moral defectuoso, y los diversos resultados para una cultura local dada son prácticamente ilimitados (Hauser, 2006). Para mí, esta discusión sobre la variación cultural no presta suficiente atención a las variables socioeconómicas responsables de configurar la cultura. Como argumenta Goldschmidt, "todo tiene que ver con la calidad de la justicia y la disponibilidad de oportunidades" (2006, p. 151). Anteriormente, Goldschmidt (1999, n.p.) había razonado que "unos motivos derivados de la cultura pueden sustituir, suplementar o dejar sin efecto un comportamiento programado genéticamente."

Insisto en ello: los datos neurofisiológicos apoyan decisivamente la idea de que la moralidad se funda en la biología. Como plantea Greene, no es algo que recibamos "desde arriba", de las altas autoridades religiosas o los filósofos, sino algo que surge "desde abajo", como consecuencia de los procesos evolutivos del cerebro (Greene en Vedantam, 2007). Ahora bien, como Rizzolatti y Craighero (2006) hacen bien en recordarnos, "Para usar el mecanismo de espejo (un mecanismo biológico) estrictamente de una forma positiva, hace falta añadir algo, algo cultural." 
No se puede defender ni una explicación biológica reductivista ni un argumento en el sentido de que "la cultura siempre puede más que la naturaleza". En vez de eso, yo me siento cómodo con lo que el teórico político William Connolly (2002) describe como “...una política a través de la cual la vida cultural interviene en la composición del proceso cuerpo/cerebro. Y vice versa." (Connolly, quien que yo sepa es la primera persona que utiliza el término neuropolítica, no se ocupa, en su erudito estudio, de la relación entre las neuronas espejo y la política de la empatía).

El reciente trabajo de Molnar-Szakacs y sus colegas sugiere que los estímulos culturales producen una impronta e influyen en determinadas respuestas neurobiológicas, y en el comportamiento subsiguiente. Además, la cultura y la identidad étnica de quienes transmiten el mensaje parecen constituir una variable crítica. Empleando la estimulación magnética transcraneal (EMT) encontraron una diferencia significativa, mensurable, en la actividad de las neuronas espejo en sus sujetos, según la persona que transmitía la información compartiera, o no, las características culturales y étnicas del sujeto. MolnarSzakacs concluyen: "Nuestros datos demuestran que tanto la etnicidad como la cultura interaccionan para influir en la actividad del cerebro, específicamente dentro de la red de neuronas espejo que interviene en la comunicación e interacción social" (Molnar-Szakacs, 2007; Preston, 2006; y en prensa). Si bien parece precipitado extraer conclusiones firmes de esta investigación muy preliminar, sin duda está garantizado que se va a seguir investigando sobre los lazos entre la cultura y la codificación de las neuronas espejo, sobre todo por la posibilidad de unas profundas implicaciones políticas.

Aquí volvemos a nuestra cuestión anterior sobre la relativa ausencia de respuestas empáticas amplias dentro de la sociedad. Las culturas rara vez son fenómenos neutros, inocentes, sino que se organizan conscientemente para premiar a determinadas personas y penalizar a otras. Como Parenti (2006) razona convincentemente, determinados aspectos de la cultura pueden funcionar como instrumentos de poder social y dominio social a través del adoctrinamiento ideológico.

La cultura es un terreno muy reñido, y su estudio puede revelar cómo se ejerce el poder, y en nombre de quién. Aquí el manual es el análisis clásico de Gramsci (1971) de la hegemonía cultural en la cual el capitalismo mantiene el dominio, en parte, creando de modo sutil pero activo las normales culturales que prevalecen en la sociedad. Este control consensuado se logra a través de los medios de comunicación de masas, la educación, la religión y la cultura popular, a medida que las clases subordinadas asimilan ciertas ideas como "sentido común".

Cohen y Rogers, analizando la crítica de Chomsky de las elites, señalan que " Una vez que existe un orden injusto, quienes se benefician de él tienen un interés por mantenerlo, y, en virtud de sus ventajas sociales, tienen también el poder para hacerlo." (Cohen, 1991, p. 17) (Véase un tratamiento conciso, pero no carente de crítica, de los 
puntos de vista sociales y éticos de Chomsky en Cohen, 1991.) Claramente, la tan alardeada capacidad humana para la comunicación verbal funciona en ambos sentidos. En las manos equivocadas, a menudo se abusa de esta capacidad, ahogando conscientemente la respuesta empática. Cuando de Waal escribe "Los animales no son filósofos morales", yo me pregunto, si al hacer esta comparación, no se estará manifestando a favor de ellos. (de Waal, 1996b, n.p.)

Uno de los métodos que se emplean en las democracias capitalistas es la "fabricación del consentimiento" de Chomsky y Herman, una forma muy sofisticada de control del pensamiento. A los ciudadanos potencialmente activos hay que "distraerlos de sus intereses reales, y confundirlos deliberadamente sobre el modo en que funciona el mundo" (Cohen, 1991, p. 7; Chomsky, 1988).

En este ensayo, y siguiendo a Chomsky, yo mantengo que el cerebro humano es el primer objetivo de esta "crianza" perversa, o propaganda. En el contexto de este artículo podríamos reformularlo diciendo que la red de neuronas espejo del cerebro humano es el objetivo al que va dirigida esta fabricación de ignorancia e indiferencia porque la exposición a determinadas nuevas verdades acerca de la empatía (pruebas incontestables de nuestra naturaleza moral innata) suponen una amenaza directa a los intereses de las elites. No hay ningún fantasma en la máquina, pero la maquinaria capitalista intenta mantener a la gente a raya con un fantasma ideológico, la noción de una identidad construida sobre los valores de mercado. Pero “...si nadie se viera a sí mismo como el capitalismo necesita que se vea, la propia dignidad de cada persona evitaría que el sistema los explotara y manipulara." (Kelleher, 2007) Es decir, dada la aparente universalidad de esta predisposición biológica hacia la empatía, contamos con una potente línea de fondo científica desde la cual lanzar nuevas críticas a la manipulación por las elites, este culto a la crueldad.

En primer lugar, los orígenes evolutivos y biológicos de la empatía aportan pruebas empíricas sólidas (no se trata de pensamientos ilusorios, ni siquiera de inferencias lógicas) a favor de la construcción de unas sociedades muchísimo mejores. En esa línea, estas nuevas investigaciones son del todo coherentes con el trabajo sobre la naturaleza del amor auténtico y la expresión concreta de ese amor en forma de afecto, esfuerzo, responsabilidad, valentía y respeto. Como nos recuerda Eagleton, si los demás también se apuntan a este comportamiento "...el resultado es una forma de servicio recíproco que brinda el contexto en el que puede prosperar cada individuo. El nombre que tradicionalmente se le da a esta reciprocidad es amor." Dado que la reciprocidad exige la igualdad y poner fin a la explotación y la opresión, se sigue que "el tratar a los demás de forma justa y compasiva es, a gran escala, una de las condiciones para que el individuo pueda desarrollarse." Y en cuanto animales sociales, cuando actuamos de este modo estamos haciendo realidad nuestra naturaleza "en su aspecto más excelente". (2007, pp. 170, 159-150, y 173). (Allot (1992) proporcionó, hace ya tiempo, in informe de la historia evolutiva del amor y su significado para el desarrollo y la supervivencia humana). 
El ansia depredadora, la crueldad, la barbarie, etc., son también aspectos de nuestra naturaleza, que tienen sus orígenes evolutivos y sus correlatos neuronales. Como ha escrito Chomsky, "Si ves a alguien matar a un niño a palos, deberías decir, "bueno, eso es la naturaleza humana" y ciertamente lo es: sin duda hay condiciones bajo las cuales la gente actúa precisamente así. En la medida en que esta afirmación es cierta, y esa medida existe, simplemente no es relevante: la naturaleza humana también tiene la capacidad de conducir hacia el altruismo, y la cooperación, y el apoyo, y la solidaridad, y una tremenda valentía, y muchas más cosas." (Chomsky, 2002, p. 356) La cuestión crítica es cómo determinar qué es lo que va a prevalecer, cómo hacer realidad una forma de entorno global que aumente las oportunidades de que florezca el aspecto empático de nuestra naturaleza.

Como he señalado en otro lugar, el clásico de Fromm El arte de amar es un virulento ataque a las fuerzas sociales y económicas que nos niegan la experiencia más gratificante de la vida y "la única respuesta satisfactoria al problema de la existencia humana". Para Fromm, el entender cómo la sociedad configura nuestros instintos humanos, y por tanto nuestro comportamiento, es a su vez la clave para comprender por qué el "ama a tu prójimo", el amor hacia el desconocido, es algo tan difícil de alcanzar en la sociedad moderna.

La cultura capitalista global que premia la acumulación y los beneficios no sólo devalúa la actitud empática, sino que da lugar a un carácter atrofiado en el cual todo se transforma en una mercancía, no solamente las cosas, sino los propios individuos. La misma capacidad de practicar la empatía (el amor) se subordina a nuestra religión de estado del mercado, en el cual cada persona busca su beneficio en una competencia alienante e interminable, ávida de mercancías.

Hace más de cinco décadas, Fromm argumentó, de manera convincente, que "los principios de la sociedad capitalista y los principios del amor son incompatibles" (Fromm, 1956, p. 110). Toda persona honesta sabe que las características principales de la sociedad capitalista tienden a producir individuos alienados de sí mismos, personalidades tullidas a quienes se les ha robado su humanidad, y que están en una lucha perpetua por expresar el amor empático. No es de extrañar que Fromm creyera que se necesitan cambios radicales en nuestra estructura social e instituciones económicas si la empatía/el amor han de ser algo más que un extraño logro individual y un fenómeno socialmente marginal. Él comprendió que esto sólo será posible cuando el sistema económico esté al servicio de los hombres y mujeres, y no al contrario (Olson, 2006).

La narrativa cultural dominante del hiper individualismo se está poniendo en duda, y se está minando esa estrategia insidiosa y efectiva consistente en convertir la naturaleza humana en el chivo expiatorio, diciendo que a todos nos mueve el interés egoísta y rapaz, que "el hombre es un lobo para el hombre". Desde el pecado original hasta el "gen egoísta" 
actual, ciertas interpretaciones de la naturaleza humana, invariablemente, han frenado la conciencia de clase. Los resultados de estas nuevas investigaciones contribuyen a refutar la aseveración de que las personas son, por naturaleza, poco cooperativas, un argumento al que se recurre con frecuencia para intimidar y convencer a la gente de que es fútil buscar una mejor sociedad para todos. Si se le desprende de otra racionalización más del imperio, el comportamiento depredador en nombre del modo capitalista de producción se hace más transparente aún. Y aprender acerca de la inhibición consciente de este núcleo esencial de nuestra naturaleza debería eludir las preguntas inquietantes sobre los motivos que se ocultan detrás de otras ideologías generadas por las elites, desde el neo-liberalismo hasta la "guerra al terrorismo."

En segundo lugar, hay implicaciones para estudiantes y profesores. El cultivar el compromiso empático a través de la educación sigue siendo una empresa que no se comprende bien. Los estudiantes universitarios, por ejemplo, tal vez oigan "los gritos de la gente", pero las ondas de sonido morales se amortiguan al pasar por una serie de poderosos deflectores culturales. Williams (1986, p. 143) señala que "Aunque puedan ser modelos de compasión y generosidad para quienes se encuentran en sus círculos inmediatos, muchos de nuestros alumnos tienen un punto ciego en lo que respecta a sus responsabilidades en el orden sociopolítico. En el lenguaje tradicional, se les da bien la caridad y mal la justicia."

Nussbaum (1997) defiende el plan de educación americana liberal en cuanto que cultiva una imaginación empática. Mantiene que el comprender las vidas de los desconocidos y alcanzar una ciudadanía global cosmopolita puede conseguirse a través de las artes y la humanidades. No hay muchas pruebas sólidas que apoyen este optimismo, y mi propia visión sobre las prácticas que fomentan la empatía en las universidades de USA es bastante menos entusiasta. Nussbaum da ejemplos anecdóticos de gente que se pone en el lugar de otras personas, pero rara vez da una respuesta plausible a la pregunta de por qué estas personas tal vez carezcan de lugar; o de un trabajo decente, una mínima cobertura sanitaria, una esperanza de vida elevada. El espacio dentro de los contextos educativos está totalmente infrautilizado, en parte porque no sabemos suficiente acerca de los intersticios propicios donde la pedagogía crítica podría marcar la diferencia. Se podría decir que la barrera más importante es la duda cínica, casi desesperante acerca de la existencia de un instinto moral de empatía. Las nuevas investigaciones aplacan esta duda y hacen bien en poner el énfasis en estrategias destinadas a cultivar la empatía e identificarse con "el otro". Unir las dimensiones afectivas y cognitivas de la empatía tal vez requiera una versión arriesgada de pedagogía radical (Olson, 2006, 2007a; Gallo, 1989). Una consecuencia fascinante es que el carácter percibido del profesor al que se "refleja" puede ser, al menos, tan importante como el mensaje que se imparte. Las pruebas obtenidas en una situación lúdica con estudiantes de medicina apuntan convincentemente a que las respuestas empáticas se pueden intensificar de forma considerable cuando se tiene mayor conocimiento de las necesidades específicas de los demás - en este caso, los ancianos (Varkey, 2006). Es probable que unas experiencias anteriores limitadas afectarían a la 
respuesta emocional del individuo. Una vez más, se trata de una cuestión de cultura política/adquisición de información que debe seguir estudiándose.

En tercer lugar, para mucha gente la incompatibilidad fundamental entre el capitalismo global y la expresión viva de los sentimientos morales puede llegar a resultar obvia por primera vez. (Olson, 2006, 2005) Por ejemplo, la incapacidad de experimentar este sentimiento moral tiene implicaciones radicales, entre ellas consecuencias para el planeta. Dentro de los próximos 100 años, se habrán extinguido la mitad de las especies que existen en la actualidad. Los grandes simios, los osos polares y los elefantes van camino a la extinción debido al crecimiento desaforado, la destrucción del hábitat y la caza furtiva. Serán estas actividades humanas, y no la extinción aleatoria, las que anularán millones de años de evolución (Purvis, 2000). Como dice Leakey, "Como quiera que lo miremos, estamos destruyendo la Tierra a una velocidad comparable con la de un asteroide gigante que se estrella contra el planeta..." Y los investigadores en la Universidad McGill han demostrado que la desigualdad económica está relacionada con una tasa elevada de pérdida de biodiversidad. El autor sugiere que las reformas económicas pueden ser el requisito previo para salvar la riqueza del ecosistema e insisten en que “...si podemos aprender a compartir los recursos económicos de manera más justa con los demás miembros de nuestra especie, tal vez esto ayude a compartir los recursos ecológicos con las demás especies" (Mikkelson, 2007, p. 5).

Si bien uno duda a la hora de atribuir demasiado potencial de transformación a esta capacidad emocional, es perfectamente coherente llamar más la atención sobre la empatía interespecies y la ecoempatía. Esta última puede ser esencial para la protección de las comunidades bióticas. Decety y Lamm (2006, p. 4) nos recuerdan que "uno de los aspectos más chocantes de la empatía humana es que puede ir dirigida hacia cualquier individuo, incluso a individuos de una especie distinta."

Esto ya se prefiguró hace al menos cincuenta años, cuando Paul Mattick, escribiendo sobre la noción de ayuda mutua de Kropotkin, señaló que “...Desde hace mucho tiempo, sin embargo, la supervivencia en el mundo animal no sólo depende de la práctica de, o bien la ayuda mutua o la competencia, sino que viene determinada por decisiones de los hombres sobre qué especies deben prosperar y cuáles deben ser exterminadas (...). Allí donde gobierna el hombre, las "leyes de la naturaleza" dejan de existir." Esto es igualmente aplicable a los humanos, y Mattick observó, con razón, que las demandas de la acumulación de capital y las relaciones sociales capitalistas anulan y excluyen la ayuda mutua. Como tales, los resultados de la neurociencia son bienvenidos y necesarios, pero son en sí mismos insuficientes. Para que reine la empatía, deben desaparecer las relaciones de clase (Mattick, 1956, pp. 2-3).

En cuarto lugar, y esto es igual de preocupante para las elites, la conciencia de esta realidad contiene el potencial para fomentar unas actitudes cosmopolitas que 
"desestabilizan" pero afirman la humanidad hacia el "otro" desconocido, tanto aquí como en el extranjero. Como tan bien lo dice de Waal, "la empatía puede anular cualquier regla sobre cómo tratar a los demás.” (de Waal, 2005, p. 9) Amin (2003), por ejemplo, propone que la nueva Europa reciba un nuevo marco en una ética de empatía y compromiso con el desconocido como su valor nuclear. La disminución de la empatía dentro de la cultura reduce el comportamiento prosocial y la cohesión social. Dadas las peligrosas fuerzas centrífugas del etnonacionalismo y la xenofobia, resulta absolutamente necesario este tema unificador, que al mismo tiempo abrirá un espacio a una Europa aún no definida, un pueblo del futuro.

Finalmente, como observa de Waal, "Si fuéramos capaces de ver a la gente de otros continentes como parte de nosotros, incluyéndolos en nuestro círculo de reciprocidad y empatía, estaríamos basándonos en la naturaleza , en vez de ir en contra de ella." (de Waal, 2005 , p. 9) Una ética de la empatía constituye una parte esencial de lo que significa ser humano, y las sociedades que carecen de ella, las sociedades que no satisfacen esta necesidad, deberían ser deficientes. Se nos ha negado, de forma sistemática, un compromiso más profundo y más gratificantes con este sentimiento moral. Yo diría que la enorme cantidad de engaños y fraudes que se invierten para dejar sin efecto la empatía son un motivo de esperanza, de optimismo prudente. Paradójicamente, la relativa ausencia de un comportamiento empático generalizado es, de hecho, un valioso tributo a su poder potencialmente subversivo.

¿Es excesiva la esperanza de que estamos a punto de descubrir un punto fijo arquimediano moral, con base científica, en el que podamos hacer palanca para dirigir el discurso público hacia una apreciación de nuestra auténtica naturaleza, la cual, a su vez, podría liberar poderosas fuerzas de emancipación? 


\section{Bibliografía}

Adolphs, R., Damasio, H., Tranel, D., Cooper, G., Damasio, A.R. (2000), “A role for somatosensory cortices in the visual recognition of emotion as revealed in three-dimensional lesion mapping", Journal of Neuroscience, 20: 2683-2690.

Albert, M. (n.d.), “Universal Grammar and Linguistics”, www.zmag.org/Zmag/articles

Allot, R. (1992), "Evolutionary Aspects of Love and Empathy", Journal of Social and Evolutionary Systems, 15, 4, 353-370.

Amin, A. (2003), "From ethnicity to empathy: a new idea of Europe", www.opendemocracy.net/debates/articles 24-7-2004.

Barber, N. (2004), Kindness in a Cruel World, Pantheon, New York, pp. 203-231.

Bennett, J. (2005), Empathetic Vision: Affect, Trauma, and Contemporary Art, Stanford University Press, Stanford, CA.

Blair, J., Mitchell, D., and Blair, K. (2005), The Psychopath: Emotion and The Brain, Blackwell, Oxford, UK.

Blakeslee, S. (2006), “Cells That Read Minds”, The New York Times, 1/10/06.

Brooks, D. (2007), “Human Nature Redux”, The New York Times, 2/16/2007.

Carey, B. (2006), “Messages from Mouse to Mouse: I feel your pain”, New York Times, July 4.

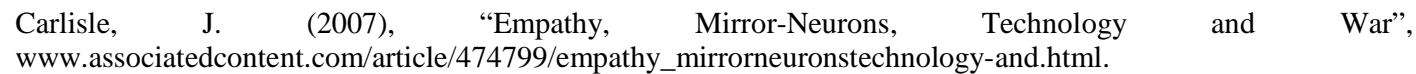

Chomsky, N. (1971), Human Nature: Justice versus Power, Noam Chomsky debates Michel Foucault, www.chomsky.info/debates

Idem (1988), Language and Problems of Knowledge: The Managua Lectures. MIT Press, Cambridge, MA.

Idem (2002), Understanding Power: The Indispensable Chomsky, The New Press, New York.

Idem (2005a), "What We Know”, Boston Review (Summer) 
Idem (2005b), "Universals of Human Nature”, Psychotherapy and Psychomatics, 74.

Chomsky, N. and Herman, E. (1988), Manufacturing Consent: The Political Economy of the Mass Media, Pantheon, New York.

Cleckley, H. (1941), The Mask of Sanity, Mosby, St. Louis.

Cohen, C. and Seu, B. (2002), "Knowing Enough Not To Feel Too Much”, in Mark Philip Bradley and Patrice Petro, Truth Claims, Rutgers University Press, New Brunswick, 187-201.

Cohen, J. and Rogers, J. (1991), "Knowledge, Morality and Hope: The Social Thought of Noam Chomsky”, New Left Review, 187, pp. 5-27.

Cookman, C. (2007), "An American Atrocity: The My Lai Massacre Concretized in a Victim's Face," The Journal of American History, 94, 1, June 2007.

Connolly, W. (2002), Neuropolitics, University of Minnesota Press, Minneapolis.

D'Addelfico, G. (n.d.), The Educative Value of Empathy with the Capability Approach, www.capabilityapproach.com/pubs/13dAddelfic.

Damasio, A. (2007), "Neuroscience and Ethics: Intersections”, The American Journal of Bioethics, 7 (1): 3-7.

Damasio, A. R., Tranel, D. and Damasio, H. (1990), "Individuals with sociopathic behavior caused by frontal damage fail to respond automatically to social stimuli", Behavioral Brain Research, 41, 81-94.

Damasio, A. R. (1994), Descartes' Error, Putnam (Grosset Books), New York.

Dean, C. (2004), The Fragility of Empathy After the Holocaust, Cornell University Press, Ithaca.

Decety, J. \& Jackson, P. (2004), “The Functional Architecture of Human Empathy", Behavioral and Cognitive Neuroscience Review, 3, 71-100.

Decety, J. (2006), “Mirrored Emotion”, Interview, The University of Chicago Magazine, 94, 4, pp. 1-9.

Decety, J. and Lamm, C. (2006), "Human Empathy through the Lense of Social Neuroscience", The Scientific World Journal, 6, 1146-1163.

de Waal, F.B.M. (1996a), Good Natured: The Origins of Right and Wrong in Primates and Other Animals, Harvard University Press, Cambridge, MA.

Idem (1996b), Emory Magazine, in Brief, Summer. 
Idem (2006), Primates and Philosophers: How Morality Evolved, Princeton University Press, Princeton, NJ.

Idem (2005-06), “The Evolution of Empathy”, Greater Good, Fall-Winter, pp. 8-9.

Idem (2007a), “The 'Russian Doll’ Model of Empathy and Imitation”, in S. Braten (Ed.) (2007) On Being Moved, John Benjamins Publishing Company, Amsterdam.

de Waal Interview (2007b), “Frans De Waal”, Interview with Tamler Sommers, The Believer, 5, 7, n.p.

Eagleton, T. (2007), The Meaning of Life, Oxford University Press, New York.

Editorial (July 2004), “Brain Scam?” Nature Neuroscience, 7, 683.

Editorial (2007), "Evolution and the Brain", Nature, 447, 7146, 14 June.

Egan, D. (2007), “How Horror Sparks Our Brains”, thetyee.ca/News/2007/03/02MirrorNeurons.

Eldridge, J. (2005) "What Effects Does the Treatment of Violence in the Media Have on People's Conduct? A Controversy Reconsidered", in Hurley (2005) pp. 243-55.

Farmer, P. (2003) Pathologies of Power: Health, Human Rights, and the New War on the Poor, University of California Press, Berkeley, CA.

French, L. (2002) "Exhibiting Terror", in Mark Philip Bradley and Patrice Petro, Truth Claims, Rutgers University Press, New Brunswick, 131-155.

Fromm, E. (1956) The Art of Loving, Harper \& Row, New York.

Gallese, V., Fadiga, L., Fogassi., and Rizzolatti, G. (1996), “Action recognition in the premotor cortex”, Brain, 1192: 593-609.

Gallese, V. (n.d.), "Mirror Neurons and Intentional Attunement: A Commentary on David Olds.", www.unipr.it/arpa/mirror/pubs/pdffiles/Gallese/olds.

Gallo, D. (1989) "Educating for Empathy, Reason, and Imagination”, Journal of Creative Behavior, 23, 2, pp. 98115 .

Ganguli, I. (2006), "Mice show evidence of empathy", The Scientist, June 30, http://www.thescientist.com/news/display/23764.

Gintis, H., Bowles, S., Boyd, R., and Fehr, E. (2004), "Explaining altruistic behavior in humans", Evolution and Human Behavior, 24, pp. 153-172. 
Idem (2005a), Moral Sentiments and Material Interests, MIT Press, Cambridge, MA.

Idem (2005b), Moral Sentiments and Material Interests: The Foundation of Cooperation in Economic Life, MIT Press, Cambridge, MA.

Goldschmidt, W. (1999), "Causation to motivation: the margin between biology and culture", www.sscnete.ucla.edu/anthro/bec/papers/Goldschmidt April 12.

Goleman, Daniel. (2006), Social Intelligence, Bantam, New York.

Gouskos, C. (2006), “Empathy and Conditioning Violence”, www.gamespot.com/features/6143438/index.

Grafman, J. (2007), in Vedantam, S., "If It Feels to be Good, It Might Be Only Natural", www.washingtonpost.com/wp-dyn/content/article/2007/05/27.

Gramsci, A. (1971), Selections from the Prison Notebooks, International Publishers, New York.

Green, J. (2007), in Vedantam, S., "If It Feels to be Good, It Might Be Only Natural", www.washingtonpost.com/wp-dyn/content/article/2007/05/27.

Grossman, D. (1996), On Killing: The Psychological Cost of Learning to Kill in War and Society, Little, Brown and Company, Boston.

Halpern, J. (1993), "Empathy: Using Resonance Emotions in the Service of Curiosity”, in Howard M. Spiro et al, eds., Empathy and the Practice of Medicine, Yale University Press, New Haven.

Halpern, J. and W. Weinstein (2004), "Rehumanization and the Other: Empathy and Reconciliation", Human Rights Quarterly, 26, 3, 561-583.

Hare, R. D. (1996), "Psychopathy and antisocial personality disorder: A case of diagnostic confusion", Psychiatric Times, 13, 2, 39-40.

Hauser, M. D. (2006a), Moral Minds, Harper Collins, New York.

Idem (2006b), “The Bookshelf Talks with Marc Hauser”, American Scientist, www.americanscientist.org

Henretig, B. (2008), "Translating passive viewership to action: a 'Hub' for human rights video", www.techforpeace.org/?tag=video

Henrich, J., Boyd, R., Bowles, S., Camerer, C., Fehr, E., Gintis, H., McElreath, R., Alvard, M., Barr, A., Ensminger, J., Hill, K., Gil-White, F., Gurven, M., Patton, J., Smith, N., and Tracer, D. (2005), "Economic Man" in Cross-Cultural Perspective: Economic Experiments in Fifteen Small-Scale Societies", Behavioral and Brain Sciences, 28(6): 795-838. 
Henrich, J., Boyd, R., Bowles, S., Gintis, H., Fehr, E. and Camerer, eds. (2004), Foundations of Human Sociality: Economic Experiments and Ethnographic Evidence in Fifteen Small-Scale Societies, Oxford University Press, London.

Henrich, J. and Henrich, N. (2006), "Culture, evolution and the puzzle of human cooperation", Cognitive Systems Research, 7, 221-245.

Hodges, S.D. and Klein, K.J.K. (2001), "Regulating the costs of empathy: the price of being human", The Journal of Socio-Economics, 30, 437-452.

Hurley, S. and Chater, N. (2005), Perspectives on Imitations, v. 2., MIT Press, Cambridge.

Iacoboni, M. (2007), "Neuroscience Will Change Society", EDGE, The World Question Center, http:www.edge.org/q2007pp14-15

Iacoboni, M. (2008a, proofs), Mirroring People, Farrar, Strauss and Giroux, New York.

Iacoboni, M. (2008b), http://video.aol.com/video-detail/authorsgoogle-macro-iacoboni, (June 10)

Jackson, P. L., Meltzoff, A. N., and Decety, J. (2004), “How do we perceive the pain of others?", Neuroimage, 125, pp. 5-9.

Jackson, P. L., Rainville, P., and Decety, J. (2006), “To what extent do we share the pain of others?”, PAIN, 125, pp. 5-9.

Jacob, M. (1987), The Cultural Meaning of the Scientific Revolution, Temple University Press, Philadelphia, PA.

Jensen, R. (3/20/02), "The Politics of Pain and Pleasure", Counterpunch.

Katz, L. D., ed. (2000), Evolutionary Origins of Morality, Imprint Academic, Bowling Green, OH.

Kazanowski, M., Perrin, K., Potter, M., and Sheehan, C. (2007), “The Silence of Suffering”, Journal of Holistic Nursing, 25, 3, 195-203.

Kelleher, W.J. (2007), “Critique of Steven Pinker’s Blank Slate”, http://www.empathicscience.org/pinker.html

Kidder, T. (2003), Mountains Beyond Mountains, Random, New York.

Killen, M. and Cords, M. (2002), "Prince Kropotkin's Ghost", American Scientist, 90, 3, p. 208.

Knight-Jadezyk (2003), “Official Culture in America: A Natural State of Psychopathy?", Sign of the Times, July, 2003. 
Koenigs, M., Young, L., Adolphs, R., Tranel, D., Cushman, F., Hauser, M., Damasio, A. (2007), "Damage to prefrontal cortex increases utilitarian moral judgments", Nature, Apr 19; 446 (7138): 865-6.

Kropotkin, P. (1972), Mutual Aid. Boston: Extending Horizons; originally (1902), London: Heinemann.

Lakoff, G. (2001), “Metaphors of Terror”, www.press.uchicago.edu/News/911lakoff./html
Lakoff,
G.
(2005),
"On
Theology
and
Politics,"
www.rockridgeinstitute.org/research/lakoff/TheologyAndPolitics.pdf

Lamm, C., Batson, C., and Decety, J. (2007), "The Neural Substrate of Human Empathy: Effects of Perspectivetaking and Cognitive Appraisal”, Journal of Cognitive Neural Science, 19: 1, pp. 42-58.

Leakey, R. and Lewin, R. (1978), People of the Lake, Doubleday, New York.

Lee, N., Broderick, A., and Chamberlain, L., "What is 'neuromarketing'?: A discussion and agenda for future research", International Journal of Psychophysiology, 63, 199-204.

Lindsay, R. (2008), “Capitalism Normalizes Sociopathy”, http://robertlindsay.blogspot.com/2008/5/capitalism.

Mattick, P. (1956), "Kropotkin on Mutual Aid - Review", Western Socialist, Boston (January-February) in www.marxists.org/archive/mattick-paul/1956/kropotkin.htm

May, T. (2006), “Terms of Empathy”, (Dana Foundation) www.dana.org/news/brainwork/detail.aspx

Mikkelson, G. M., Gonzalez, A., and Peterson, G. D. (2007), "Economic Inequality Predicts Biodiversity Loss", PLOS ONE 2 (5):e444.doi:10.1371/journal.pone.0000444.

Miller, B., Seeley, P., Mychack P., Rosen, H., Mena, I., and Boone, K. 2001), "Neuroautonomy of the self: Evidence from patients with frontotemporal dementia", Neurology, 57, 5, pp. 817-821.

Mogil, J.S. (2006), "Social Modulation of Pain as Evidence for Empathy in Mice”, Science, 312, 5782, pp. 19671970.

Molnar-Szakacs, I.; Wu, A., Robles, F. and Iacaboni, M. (2007a) "Do You See What I Mean? Corticospinal Excitability During Observation of Culture Specific Gestures", PLoS ONE, 2 (7): e626, doi:10.1371/journal.pone.0000626.

Molnar-Szakacs, I. (2007b), Cited in "Culture Influences Brain Cells: Brain's Mirror Neurons Swayed by Ethnicity and Culture”, University of California-Los Angeles (2007, July 23) Science Daily.

New Scientist (2007), “ “Altruistic’ chimps acted for the benefit of others”, NewScientist.com. 25 June.

Nussbaum, M. (1997), Cultivating Humanity, Harvard University Press, Cambridge. 
Idem (2001), Upheavals of Thought: The Intelligence of Emotions, Cambridge University Press, Cambridge, UK.

Nussbaum, M. (2006), Frontiers of Justice, The Belknap Press of Harvard University, Cambridge, MA.

Olson, G. (2005), “Scapegoating Human Nature”, ZNet, 11/30/05.

Idem (2006), "Graduates face choice between love or 'selling out' ”, ZNet Commentary.

Idem (2007a, 1987), “Execution Class”, Z Magazine, 20, 3, March, 2007.

Idem (2007b), "Neuroscience and Moral Politics: Chomsky's Intellectual Progeny", http://www.identitytheory.com/social/olson neuro.php

Idem (2008), "The Empathic Power of Images: Civil Rights, Vietnam and Today", The Black Commentator, www.blackcommentator.com/274/274_empathic_power_images_olson

Parenti, M. (2006), The Culture Struggle, Seven Stories Press, New York.

Pierce, J. (2007), "Mice in the Sink: On the Expression of Empathy in Animals", www.environmentalphilosophy.org/ISEEIAEPpapers/2007/Pierce.pdf.

Pigman, G. W. (1995), "Freud and the history of empathy", International Journal of Psycho-Analysis, 76: 237256.

Pinker, S. (2002), The Blank Slate, Viking, New York.

Idem (2008), "What Makes Us Want to Be Good?", The New York Times, 1/12/08.

Pizarro, D. A., Detweiler-Bedell, B. and Bloom, P. (2006), "The Creativity of Everyday Moral Reasoning: Empathy, Disgust and Moral Persuasion”, in J. C. Kaufman and J. Baer (Eds.), Creativity and Reason in Cognitive Development, Cambridge University Press, Cambridge, UK.

Preston, S. and de Waal, F.B.M. (2002), "Empathy: Its ultimate and proximate bases", Behavior and Brain Sciences, 25, pp. 1-72.

Preston, S. (2006-2007), “Averting the Tragedy of the Commons”, SHIFT, 13, pp. 25-28.

Preston, S.; Bechara, A.; Damasio, H.; Grabowski, T.; Stansfield, R.; Mehta, S.; Damasio, A. (2007), "The Neural Substrates of Cognitive Empathy", Social Neuroscience, 2, (3-4), 254-275.

Purvis, A.; Agapow, P-M.; Gittleman, J. and Mace, G. (2000), "Non-random extinction and loss of evolutionary history", Science, 288, 5464, pp. 328-330.

Ramanchandran, V. (2000), "Mirror Neurons and Imitation Learning as the Driving Force Behind "the Great Leap Forward' in Human Evolution”, Edge, 69, June 29, 2000, www.edge.org/3rdculture/ramachandran/ramachandranindex.html.

Idem (2006), "Mirror Neurons and the Brain in the Vat", Edge, January 10, 2006, www.edge.org/3rdculture/ramachandran06/Ramachandran06index.html+jam.

Rediker, M. (2007), The Slave Ship, Viking, New York.

Richerson, P. and Boyd, R. (2004), Not By Genes Alone: How Cultures Transformed Human Evolution, University of Chicago Press, Chicago.

Rizzolatti, G.; Fadiga, L., Gallesa, V. and Fogassi, L. (1996), "Premotor cortex and the recognition of motor actions", Cognitive Brain Research, 3, pp. 131-141.

Rizzolatti, G. and Craighero, L. (2006), "Mirror neuron: a neurological approach to empathy, DE LAS NEURONAS ESPEJO A LA NEUROPOLITICA MO333 
www.robotcub.org/misc/review 2/06 Rizzolatti Craighero.pdf

Rizzolati, G. and Sinigalia, C. (2008), Mirrors in the Brain, Oxford University Press, New York.

Slack, G. (2007), “I feel your pain”, www.Salon.com, 2007/11/05.

Smith, A. (1759/1976), The Theory of Moral Sentiments, D. Raphael and A. Macfie (Eds.), Clarendon Press, Oxford, UK.

Solomon, N. (4/17/03), "Media and the Politics of Empathy", Media Beat.

Stanton, A. (2007), "Neural Substrates of Decision-Making in Economic Games”, Journal Dissertations, 1 (1).

Staub, Ervin (2002), in Davidson, R.J. and Harrington, A. (Eds.), Visions of Compassion, Oxford University Press, New York.

Stein, E. (1989), On the problem of empathy, ICS Publications, Washington. (Original work published in 1917) as found in D'Addelfico (n.d.).

Thomas, E. (2006), “Empathetic”, www.temple.edu/tyler/empathetic/essay.html

Trivers, R. (1971), “The evolution of reciprocal altruism”, Quarterly Review of Biology, 46, pp. 35-57.

Varkey, P., Chutka, D.S. and Lesnick, T.G. (2006), “The aging game: improving medical students' attitudes toward caring for the elderly”, J. Am. Med. Directors Assoc. 7, 224-229 in Decety, J. and Lamm, C. (2006).

Vilas, C. (1997), "Inequality and the Dismantling of Citizenship in Latin America", NACLA Report on the Americas, 31, 1 (July-August), 57-63.

Warneken, F. and Tomasello, M. (2006), "Altruistic Helping in Human Infants and Young Chimpanzees", Science, 311, No. 5765, pp. 1301-1303.

Williams, O. (1986), in Johnson, D. (Ed.), Justice and Peace Education, Orbis, New York.

Wilson, A.O. (1978), On Human Nature, Harvard University Press, Cambridge. 